DOI: $10.20396 /$ urbana.v10i1.8648813

\title{
SANTA LUCÍA IMÁGENES DE UN CERRO QUE MIRA UNA CUIDAD ${ }^{1}$
}

\author{
SANTA LÚCIA \\ IMAGES OF A HILL LOOKING TOWARDS A CITY
}

\author{
Amari Peliowski Dobbs; Catalina Valdés Echenique \\ Universidad de Chile \\ amari.peliowski@uchilefau.cl; cvaldese@gmail.com
}

\begin{abstract}
Resumen
A partir del estudio de una serie de imágenes de diversa índole, proponemos analizar los vínculos entre una ciudad y un cerro atendiendo al modo de ver panorámico y sus derivas visuales a lo largo del siglo XIX. Esto nos permite reflexionar sobre el particular rol del cerro Santa Lucía, hito de referencia para Santiago de Chile y punto de confluencia para las representaciones de esta ciudad capital. ¿Qué tipo de relaciones se pueden establecer entre el cerro y la ciudad a partir de estas imágenes? ¿En qué grado esta mirada total y en altura determina la comprensión y la construcción visual de la ciudad? Y al revés: ¿en qué grado el promontorio da forma a las imágenes de la ciudad y da lugar a un particular modo de ver? Con este recorrido visual, se pretende responder a estas y otras preguntas ligadas a la percepción del espacio y a la experiencia del paisaje urbano en el siglo XIX.
\end{abstract}

\section{Palabras clave}

Visión panorámica. Santiago de Chile. Cerro Santa Lucía. Modos de ver. Expediciones científicas. Siglo XIX.

\begin{abstract}
We propose to analyze a series of images in order to understand the relationship between a hill and a city through the interpretation of the panoramic view and its diverse visual derivations in the ninetwwnth century. This allows us to reflect on the role occupied by the Santa Lucia hill in Santiago de Chile, this hill being a point of confluence for nineteenth century representations of this capital city. What kind of connections between the hill and the city do these images convey? In what degree does this total and elevated view determine the comprehension and the visual construction of the city? And the other way around: in what degree does the hill shape the images of the city and convey a particular way of seeing? With this visual trajectory, we hope to answer these and other questions about the perception of space and the experience of urban landscape in the nineteenth century.
\end{abstract}

\section{Key words}

Panoramic view. Santiago de Chile. Santa Lucia hill. Ways of seeing. Scientific expeditions. Nineteenth century. 


\section{Introducción}

Desde que en 1787 el pintor británico Robert Barker patentó un dispositivo pictórico cilíndrico como espectáculo visual, denominándolo panorama, fijó el significado de un neologismo que luego ha servido para denominar diversas imágenes que representan una vista urbana o un paisaje visto desde un punto determinado en altura o lejanía, aun cuando dicha vista no abarque los $360^{\circ}$ de un campo de visión considerado como total ${ }^{1}$. Junto con la masificación del artefacto y de las imágenes que de alguna forma lo replicaban, la palabra panorama devino una expresión de uso corriente, un término que permite describir relaciones tanto espaciales como temporales de amplio alcance y designar lugares e instancias de sociabilidad. La extensión metafórica del término pasa así a describir un modo de ver que no es solo óptico sino epistemológico y social; una cosmovisión, en fin, que da lugar a una serie de representaciones mentales, imágenes, figuras de lenguaje, que implican la capacidad de abarcar unidades de espacio y de tiempo que abarcan un conjunto y sus detalles simultáneamente. Reconocemos en estas representaciones un gesto expresivo de los procesos de modernización que experimentan los sujetos urbanos durante el siglo XIX, en la medida que se someten -si bien, obviamente, con ritmo descompasado y en formas nada homogéneas- a las dinámicas de industrialización, migración, expansión y masificación que van dando forma a las nuevas ciudades del mundo. La mirada panorámica correspondería entonces a una explícita y determinante autopercepción de aquel sujeto moderno como observador ${ }^{2}$.

En lo que sigue, proponemos un recorrido histórico y visual de la configuración de la ciudad de Santiago de Chile como un panorama, valiéndonos del cerro Santa Lucía como punto de referencia para la configuración de la vista panorámica de la ciudad en cuyo centro está emplazado. Para ello, nos aproximaremos a este hito geográfico atendiendo a su función de mirador, que emergió de modo explícito durante el proceso de revolución de independencia de la república y encontró su auge en las últimas décadas del siglo XIX, siendo determinante en la producción de imágenes que retratan la ciudad. El cerro, de este modo, informa la mirada e identifica a Santiago, convirtiéndolo en una ciudad vista, conocida y reconocible.

El promontorio, que se eleva 90 metros por sobre la cota de la ciudad, ocupó entre los siglos XVI y XVIII la función de borde urbano escasamente habitado, siendo ocupado sólo como cementerio informal y cantera de piedras para el pavimento de la creciente ciudad ${ }^{3}$. Revisando la iconografía histórica de Santiago desde los primeros planos urbanos de mediados del siglo XVII hasta dibujos de finales del XVIII, comprobamos justamente que el cerro se reconoce como un hito natural que sirve de referencia e índice de la capital del Reino de Chile ${ }^{4}$.

\footnotetext{
${ }^{1}$ Para una historia del panorama, ver Denise OLEKSIJCZUK, The first Panoramas. Visions of British Imperialism (2000).

${ }^{2}$ Como lo ha subrayado Walter BENJAMIN, la vida urbana del siglo XIX, y específicamente en la capital francesa, se caracterizó por la exaltación del deseo visual de objetos y mercancías, determinando una separación entre observador -o también espectador y comprador- y el objeto observado. Benjamin desarrolla estas ideas principalmente en El libro de los pasajes (1935), y en La obra de arte en la época de su reproductibilidad técnica (1936). Guy DEBORD, por su parte, explota la idea de espectacularización de la sociedad moderna en La sociedad del espectáculo (1967).

3 Para una historia del cerro Santa Lucía, ver Rodrigo PÉREZ DE ARCE, Ricardo ASTABURUAGA y Hernán RODRÍGUEZ, La montaña mágica: el cerro Santa Lucía y la ciudad de Santiago (1993). Ver también la crónica histórica publicada por Criss SALAZAR en su blog Urbatorium, http://urbatorium.blogspot.com.es/2009/07/el-huelen-negro-primera-etapa-de-la.html (2009).

${ }^{4}$ Una iconografía bastante completa del cerro en este período puede encontrarse en el sitio web www.archivovisual.cl. Rodrigo PÉREZ DE ARCE escribe en este sitio sobre el compromiso entre naturaleza y urbe en su reseña "Cruzando el vacío del Llano del Maipo", referida a una imagen similar a las de la Fig. 1 y 2, disponible en http://www.archivovisual.cl/cruzando-el-vacio-del-llano-del-maipo (2011).
}

(c) Urbana: Rev. Eletrônica Cent. Interdiscip. Estud. Cid. Campinas, SP $\quad$ v.10, n.1 [18] p.232-249 jan./mai. 2018 
En estas imágenes se reiteran dos puntos de vista desde los cuales se mira la ciudad. Un primer punto consiste en la tradicional vista cenital que adopta la cartografía, donde la ciudad se ve en planta y el cerro Santa Lucía aparece como elemento identificador a un costado o integrado a la grilla urbanizada de la ciudad (figuras 1 y 2 ). El segundo punto responde al hábito común de ese período de componer imágenes cartográficas desde un punto de vista imaginario extremadamente elevado pero no necesariamente a $90^{\circ}$ con respecto del suelo, si no más bien a $45^{\circ}$. Este punto de vista "a vuelo de pájaro" permite comprender el emplazamiento de la ciudad en el valle y su posición relativa a las cordilleras de los Andes y de la Costa que lo circundan (figuras 3 y 4). En algunas imágenes cartográficas, estos dos puntos de vista se combinan, generando planos de proyección híbrida donde la grilla se ve en planta y el cerro, frecuentemente, de perfil, subrayando su condición de hito identificador de la ciudad de Santiago, aunque siempre connotando su condición de borde natural y periférico (figuras 5 y 6).

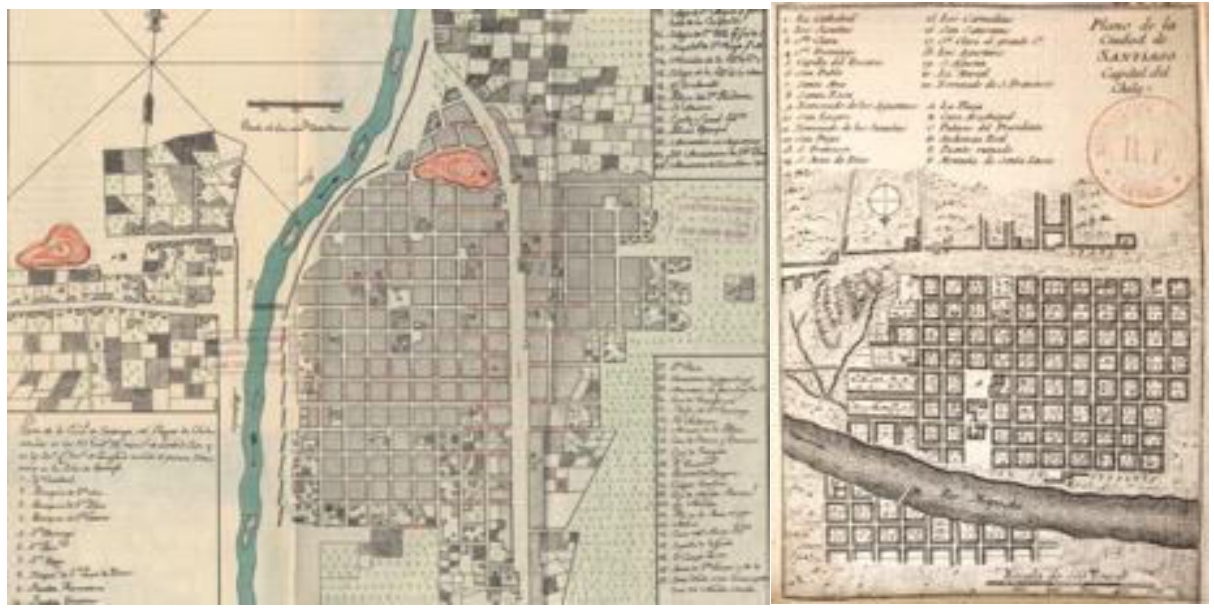

Figura 1 - Autor anónimo, Plano de la ciudad de Santiago del Reyno de Chile, siglo XVIII. Biblioteca Nacional de Chile, Santiago. Fuente: http://www.archivovisual.cl. Acceso el 29 marzo 2017.

Figura 2 - Tomás López, Plano de la ciudad de Santiago, 1758. Biblioteca Nacional de Chile, Santiago. Fuente: http://www.archivovisual.cl. Acceso el 29 marzo 2017. 


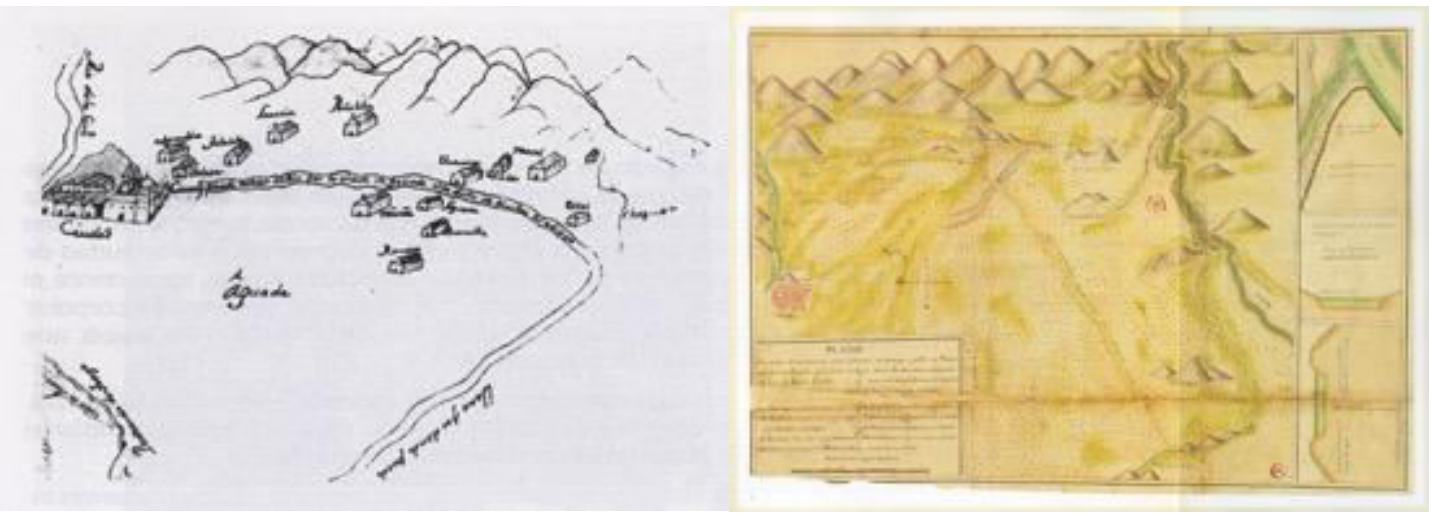

Figura 3 - Autor desconocido, Trazado del canal de San Carlos, 1743, dibujo sobre papel. Biblioteca Nacional de Chile, Santiago. Fuente: http://www.archivovisual.cl. Acceso el 29 marzo 2017.

Figura 4 - Autor desconocido, Plano de Santiago, siglo XVIII, impresión de tinta y acuarela sobre papel. Biblioteca Nacional de Chile, Santiago. Fuente: http://www.archivovisual.cl. Acceso el 29 marzo 2017.

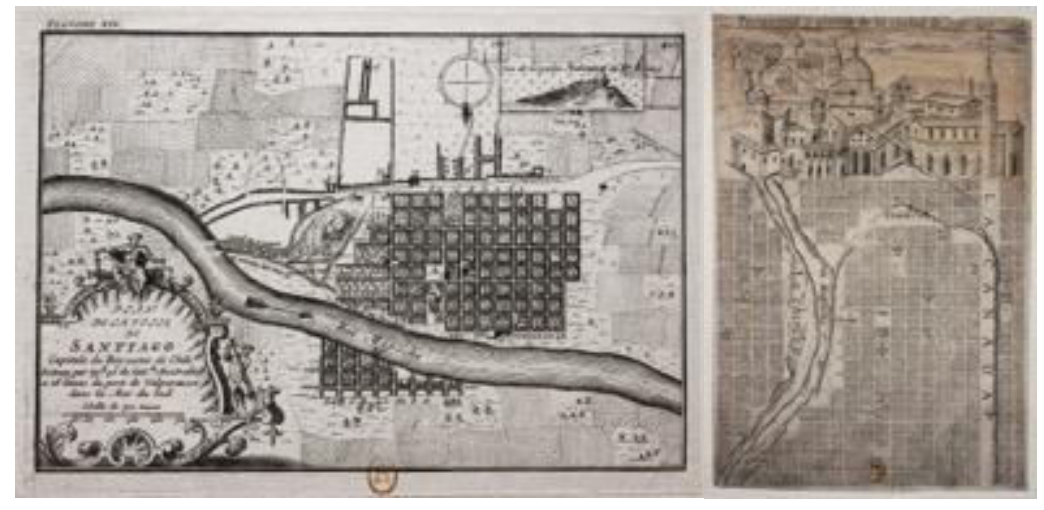

Figura 5 - Amedée François Frezier, Santiago, 1716, impresión de tinta sobre papel. Bibliothèque Nationale de France, París. Fuente: http://www.archivovisual.cl. Acceso el 29 marzo 2017.

Figura 6 - Alonso de Ovalle, Perspectiva y planta de la ciudad de Santiago, lámina incluida en Histórica relación del reino de Chile (Roma: Francesco Cavallo, 1646). Biblioteca Nacional de Chile, Santiago

En las representaciones correspondientes al siglo XIX se muestra al cerro, en cambio, como un actor urbano de la ciudad, que se sustrae de su condición de elemento natural asumiendo un carácter antrópico. El Santa Lucía replica así el gesto moderno del sujeto observador e interactúa con la ciudad y con sus habitantes permanentes y esporádicos, disponiendo dinámicas de control social, influyendo en la percepción del paisaje y determinando los sentidos de orientación ${ }^{5}$. Observando la historia visual de esta relación que se desenvuelve

${ }^{5}$ La revisión que aquí planteamos nos permite observar al cerro como un "actor no humano", según el término propuesto, entre otros, por el sociólogo francés Bruno Latour en Reensamblando lo social (2005) como parte de la teoría de actor-red, para señalar que las acciones que dan lugar a ciertos fenómenos no son llevadas a cabo únicamente por sujetos mas también por organismos de otras naturalezas e incluso objetos (en sus ejemplos, desde una bacteria a una ciudad). "Además de 'determinar' y servir como 'telón de fondo

(c) Urbana: Rev. Eletrônica Cent. Interdiscip. Estud. Cid. Campinas, SP v.10, n.1 [18] p.232-249 jan./mai. 2018 
entre el Santa Lucía y Santiago a lo largo del siglo XIX, veremos que esta interacción configura la construcción visual tanto del cerro como de la ciudad, determinando los gestos de medición espacial que, con fines científicos, componen todo tipo de cartografías, con fines de ingeniería, elevan y demarcan el trazado urbano y, con fines artísticos, revelan las formas de una ciudad en proceso de transformación.

Es posible identificar en esta historia visual tres momentos iconográficos en los que se van manifestando diferentes funciones que va cumpliendo el peñón. El primer momento corresponde a la función de atalaya que le otorgó el imperio español en sus postrimerías, a partir del cual se fija la condición del cerro como un punto de vista desde el cual se delimita un área de control militar, deviniendo así una suerte de mirilla apuntada a la ciudad. Un segundo momento corresponde a la función del hito como punto de observación científica y artística, que conlleva a la repetición del gesto de subir al cerro y representar la vista panorámica que de ahí se obtiene de la ciudad. Un tercer momento designa al cerro como mirador urbano y espacio de renovación social, dada su remodelación en paseo público en la década de 1870.

En cada uno de los momentos señalados el cerro va asumiendo diferentes roles, movilizando personajes diversos y actuando cada vez menos como hito geográfico y cada vez más como entidad cultural, cumpliendo funciones de mirilla militar, observatorio científico, punto de vista para la representación artística y espacio de contemplación y sociabilidad, provocando en el trayecto numerosas imágenes que constituyen fuentes para la historia de la ciudad, de sus habitantes y de sí mismo.

\section{El cerro como atalaya}

El cerro se fijó como atalaya de Santiago en el último año del proceso conocido como la "reconquista española" (entre 1814 y 1817) durante el cual se reimpone el poder imperial luego del primer intento de declaración de independencia o Patria Vieja en 1810. Por encargo del gobernador Casimiro Francisco Marcó del Pont, representante de Fernando VII en la Capitanía General de Chile, fueron construidas dos baterías militares que lo convirtieron en un fuerte militar contra los intentos independentistas (AMUNÁTEGUI y AMUNÁTEGUI, 1867, p. 275-276; BARROS ARANA, 1902, TOMO X: 241-43; GUERRERO, 2002). Culminadas en 1816, las baterías Marcó (hoy Plaza Caupolicán) y Santa Lucía (hoy Castillo Hidalgo), instaladas en las laderas sur y norte del cerro respectivamente, estaban armadas con cañones que apuntaban a la ciudad. Como no contamos con antecedentes de la sobrevivencia de los planos de estos fuertes, consideramos los dibujos de otra obra del mismo ingeniero encargado de su construcción, Manuel Olaguer Feliú (GUARDA, 1990 y 1973, FELIÚ CRUZ, 1937 y GREVE, 1938), y una de Mariano de Pusterla, su contemporáneo, como imágenes de referencia (figuras 7 y 8 ).

de la acción humana', las cosas podrían autorizar, permitir, dar los recursos, alentar, sugerir, influir, bloquear, hacer posible, prohibir, etc." (LATOUR, 2005, p. 107).

(c) Urbana: Rev. Eletrônica Cent. Interdiscip. Estud. Cid. Campinas, SP v.10, n.1 [18] p.232-249 jan./mai. 2018 


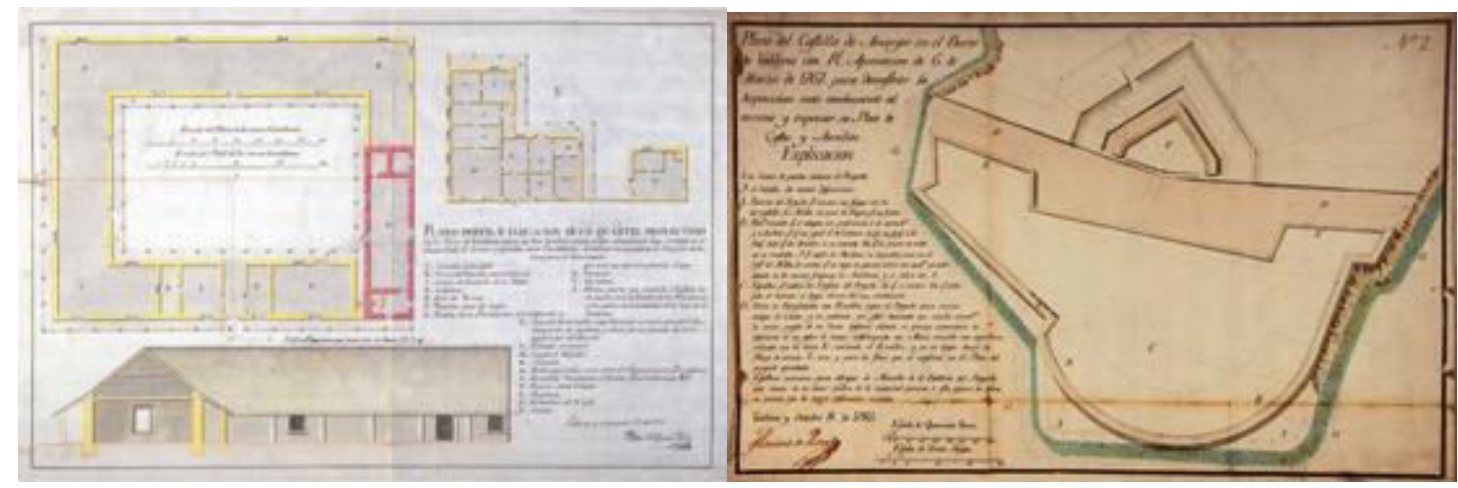

Figs. 7 - Manuel Olaguer Feliú, Cuartel proyectado en la plaza de Valdivia (1795), tinta y acuarela sobre papel. Archivo Nacional Histórico, Santiago.

Fig. 8 - Mariano de Pusterla, Plano del castillo de Amargos (1785), tinta y acuarela sobre papel. Archivo Nacional Histórico, Santiago.

Dibujos como estos son el resultado de la normalización de la planimetría arquitectónica de fines del siglo XVIII, la que se corresponde con el impulso dado a la construcción de fuertes y cuarteles con el cual el imperio borbónico pretendía asegurar y robustecer su control sobre los territorios de ultramar. En efecto, a partir de la iniciativa modernizadora de Carlos III de España, se impuso la idea a lo largo del continente americano de promover la imagen de un Estado moderno, protector y eficiente, pero también omnipresente, autoritario y controlador a través de nuevas estructuras administrativas que encontraban su materialización en renovadas infraestructuras tanto urbanas, interurbanas y rurales. En la capitanía general de Chile, esto significó la organización y construcción de nuevas sedes administrativas, nuevos caminos, puentes y canalizaciones y el reforzamiento de fortificaciones a lo largo de todo el territorio dominado por el imperio español (BRAVO LIRA, 1994). Esta acción de ocupación y racionalización territorial caracterizó la gesta de los ingenieros ilustrados europeos, tal como lo ha resaltado el historiador de la arquitectura francés Antoine Picon (PICON, 1988; 1992). La ocupación del territorio no se materializó sólo a través de la instalación de nuevas construcciones, sino que se hizo efectiva además a través de un amplio trabajo de representación del espacio ocupado, particularmente de la presencia militar, por medio de dibujos que respondían a códigos normados por el cuerpo de ingenieros ibérico (PELIOWSKI, 2015).

La transformación del cerro en base militar marca el inicio de este proceso de racionalización de un Santa Lucía hasta entonces escasamente intervenido. La dominación sobre la ciudad y sus habitantes lo es también sobre la naturaleza, tal como lo explicita el propio Marcó del Pont en su informe al rey: "Combiné la naturaleza de la situación que es la mejor que ofrece país alguno, con un mediano cerro nombrado de Santa Lucía, de proporcionada elevación en el centro, dominante de todo el circuito de la población" (BARROS ARANA, 1881-1902, tomo X: 242243). Si en las imágenes correspondientes a los siglos XVII y XVIII el cerro servía de hito indicial y borde natural del perímetro urbano, luego de esta intervención no fue más representado desde la lejanía de un punto cenital, una vista a vuelo de pájaro o desde alturas mayores circundantes, sino que asumió en sí mismo el carácter de centro, elevación con campo de visión panóptico, desde el cual se hacía posible observar la ciudad circundante.

Tal vez la primera imagen que evidencia el uso del cerro como mirador panorámico es la acuarela pintada por Charles C. Wood en 1831. Este marino británico había llegado por primera vez a Chile en 1819 como parte de una comisión científica de EEUU. En 1820 pasó a formar parte

(c) Urbana: Rev. Eletrônica Cent. Interdiscip. Estud. Cid. Campinas, SP V.10, n.1 [18] p.232-249 jan./mai. 2018 
de las filas revolucionarias de José de San Martín, participando activamente en las campañas de independencia del Perú, luego de lo cual regresó a Chile y se desempeñó como ingeniero, pintor y dibujante, siendo el primer profesor de dibujo del Instituto Nacional y autor del escudo nacional chileno, adoptado en 1834.

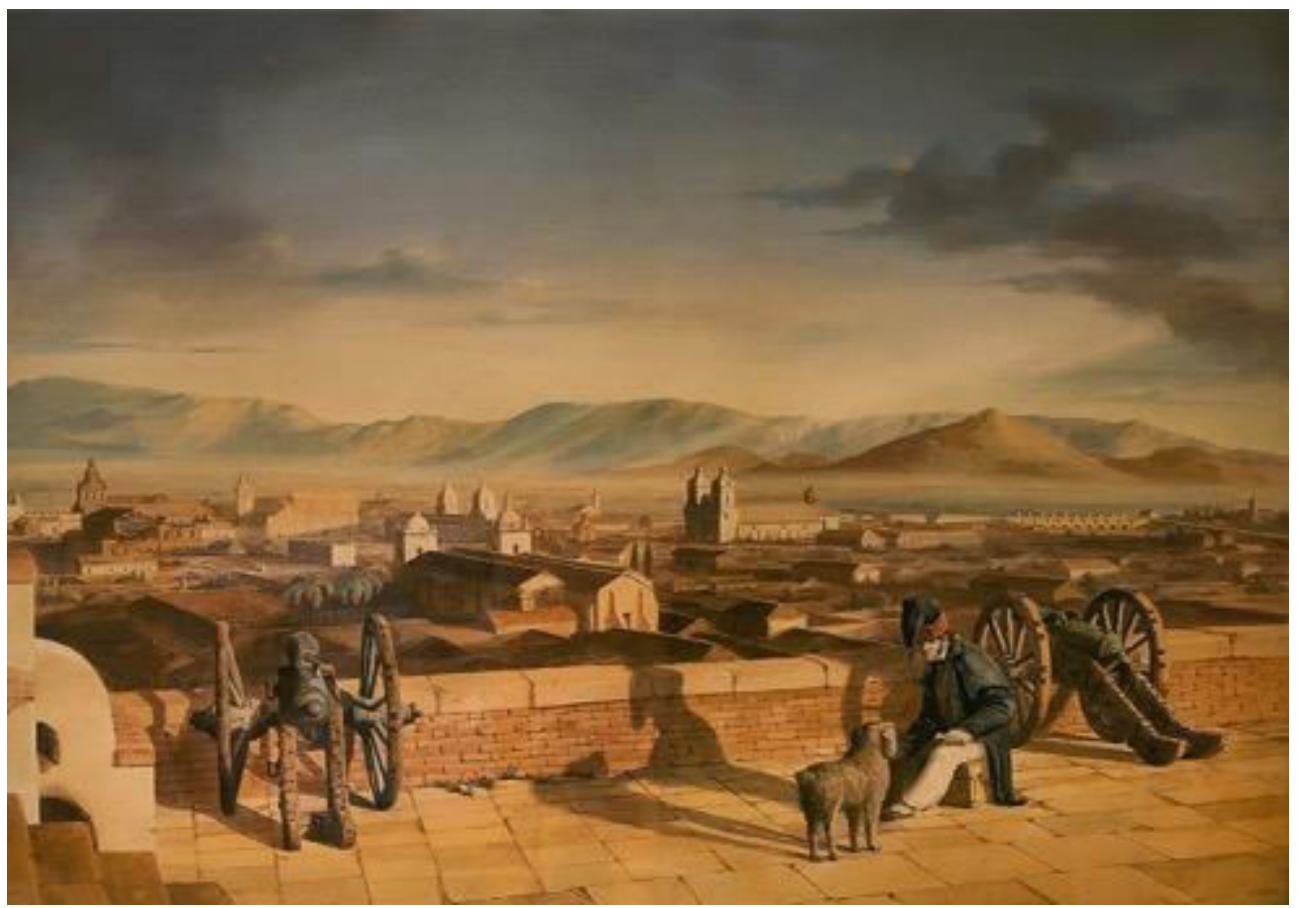

Fig. 9 - Charles C. Wood Taylor, Santiago desde el Santa Lucía (1831), tinta y acuarela sobre papel, $58 \times 81 \mathrm{~cm}$. Museo Nacional Benjamín Vicuña Mackenna, Santiago.

En la imagen (figura 9), un soldado y un perro, ubicados en la batería Hidalgo, reciben las primeras luces del amanecer que ya ilumina el sector poniente de Santiago. Desde el cerro se ve el puente Cal y Canto, los campanarios de Santo Domingo y más atrás el cerro del mismo nombre y la cordillera de la Costa, todo bañado por una bruma matutina. Si bien los cañones se mantienen apuntados hacia la ciudad, el soldado no aparece en actitud vigilante: es una escena propia de una ciudad pacificada, que se vale del antiguo fuerte español para garantizar su independencia. La acuarela corresponde a un tipo de imagen habitual entre artistas militares como Wood, poseedor de una formación de ingeniero y topógrafo y simultáneamente pintor de paisajes y marinas (SIQUEIRA BUENO, 2011). Los tres planos bien delimitados de la imagen (fuerte, ciudad, paisaje), amplifican la distancia entre el cerro Santa Lucía, cimiento de la construcción de piedras y ladrillos, y los otros cerros-isla de la ciudad que aun conservan su dimensión natural, lo cuales forman, junto con la cordillera, el fondo sostenido del paisaje característico del valle del Río Mapocho.

Para mediados del siglo XIX el cerro había perdido ya completamente su función militar y adquiría el aspecto de una inmensa ruina en medio de la creciente urbe. En dos fotografías de la década de 1860 se ve cómo los restos de las construcciones defensivas, abandonadas y monumentales, se confunden con las rocas basálticas del cerro, cada vez más horadadas para abastecer de pavimento a la ciudad (figuras 10 y 11). En una de ellas, el perfil tomado desde el

(c) Urbana: Rev. Eletrônica Cent. Interdiscip. Estud. Cid. Campinas, SP V.10, n.1 [18] p.232-249 jan./mai. 2018 
poniente de la Alameda a una altura media, integra al peñón a la grilla urbana como si de una vieja edificación se tratase y no un accidente geográfico que dificulta su continuidad. En la otra, Eugène Maunoury, autor de varios retratos de Santiago, se emplaza en la cima del cerro y muestra en primer plano la plataforma que treinta años antes había servido a Wood. Vista en picada, la apariencia del cerro es extraña, mitad de piedras montadas, mitad de roca, irregular y de ángulos rectos... una estructura híbrida que parece haber quedado olvidada a pesar de ubicarse al medio de la ciudad.

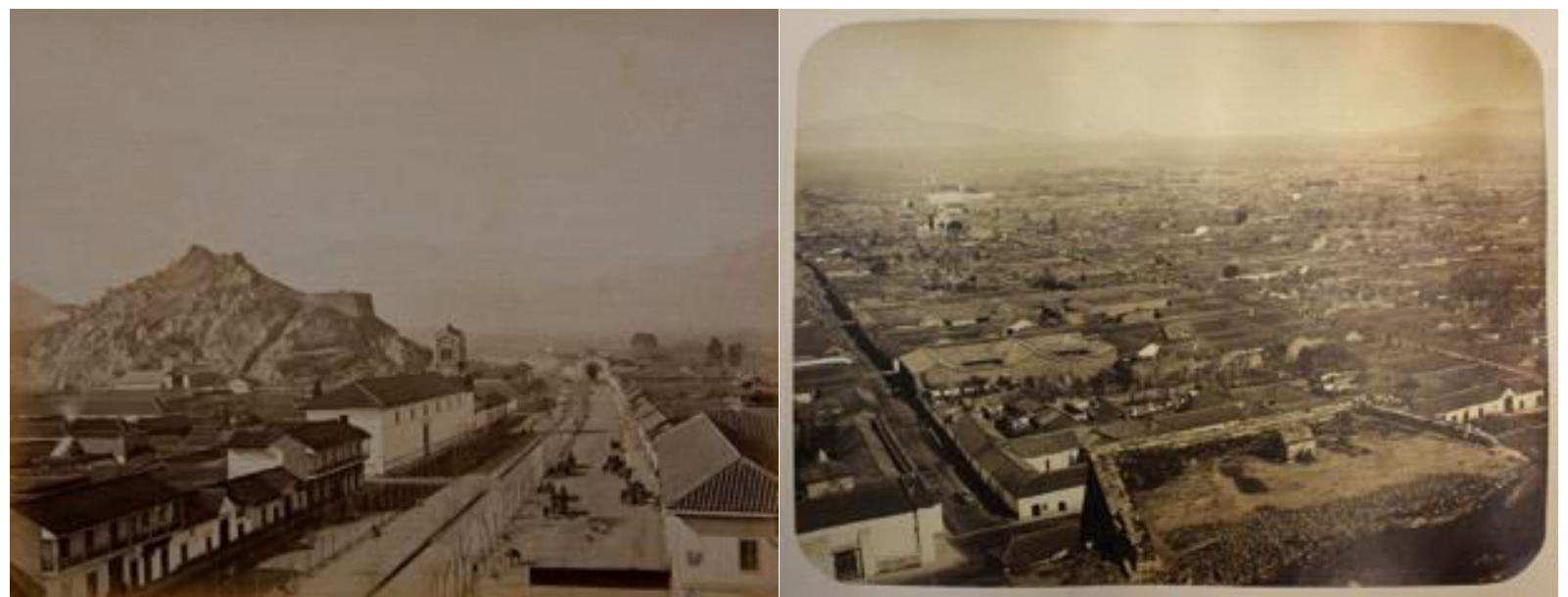

Fig. 10 - Autor desconocido. Fotografía de Santiago (1860), negativo sobre vidrio. Tomada probablemente desde el campanario de la Iglesia de San Francisco. Museo Histórico Nacional, Santiago.

Fig. 11 - Eugène Maunoury. "Rue Sainte Rose et fort Sainte Lucie", Álbum Andeken an Chile (c. 1865), impresión en papel albuminado. Biblioteca Nacional de Francia. Fuente: http://gallica.bnf.fr/ark:/12148/btv1b8443045p/f59.item. Acceso el 18 abril 2017.

\section{El cerro como observatorio}

Un segundo momento de este recuento iconográfico reconoce, a partir de mediados del siglo XIX, al Santa Lucía como un punto de observación científica y artística de la ciudad y su entorno, lugar de confluencia de nuevos actores sociales, saberes, prácticas e implementos que traducen un lugar en imagen.

Fueron los topógrafos de la Expedición Malaspina (1789-1794) los que integraron el territorio de la Capitanía general de Chile a la codificación cartográfica que por entonces comenzaba a imponerse con carácter universal en base a las medidas resultantes de la triangulación (SAGREDO y GONZÁLEZ LEIVA, 2004; GONZÁLEZ LEIVA, 2007). Es a partir de entonces que el cerro pasa a ser considerado el punto de referencia para las mediciones de extensión y relieve del territorio chileno, demarcando allí el meridiano 0 , tal como queda manifiesto en el Atlas de la geografía física de la República de Chile elaborado por Pedro José Amado Pissis y publicado en 1875 (figura 12). El naturalista francés justifica su elección explicando: "El azimut fundamental se ha obtenido por el ángulo formado por la señal situada sobre la cumbre del cerro de la Petaca, y la meridiana del antiguo observatorio del cerro Santa Lucía; es también la latitud de la cumbre de este último cerro que ha servido para calcular las de los demás vértices; y es á él que se refieren también las longitudes" (PISSIS, 1875: 308). Esta

(c) Urbana: Rev. Eletrônica Cent. Interdiscip. Estud. Cid. Campinas, SP V.10, n.1 [18] p.232-249 jan./mai. 2018 
demarcación nacional se usó durante casi un siglo de manera indistinta junto con el punto de Greenwich, antes que este último fuera asimilado como referente universal en la década del $80^{6}$.

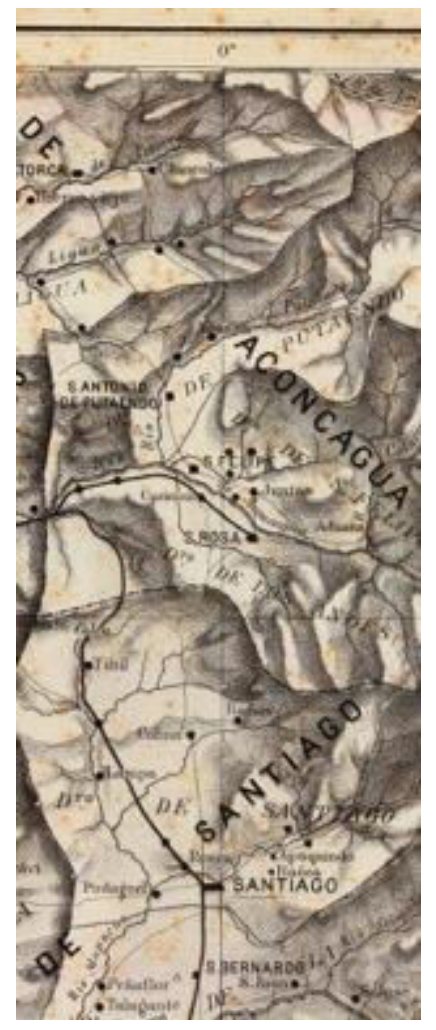

Fig. 12 - Pedro José Amado Pissis, Detalle del Plano topográfico y geológico de la República de Chile, levantado por orden del Gobierno, escala 1: 250.000. Grabado por N. Desmadryl, Impreso por Ch. Chardon, 1872-1873 (hoja 1/13), París. Mapoteca de la Biblioteca Nacional de Chile, Santiago.

Efectivamente, veinte años antes de la publicación de Pissis, los miembros de la expedición astronómico-naval proveniente de Washington (1849-1852) y comandada por James Melville Gilliss, habían reafirmado la base científica de esta demarcación al instalar en el cerro el primer observatorio astronómico moderno del Hemisferio Sur. Fue a partir de este punto que se habían propuesto medir el paralaje solar, triangulando con el observatorio astronómico del Washington, ubicado en el mismo meridiano que Santiago (HUFFMAN, 1991). Tal como comenta el propio Gilliss en el primero de los seis volúmenes de su informe The U.S. Naval Astronomical Expedition to the Southern Hemisphere during the Years 1849 -'50-'51-'52 (Washington, 1855), Ios miembros de esta expedición pasaban una buena porción del tiempo en el cerro, observando de

\footnotetext{
${ }^{6}$ Las discusiones sobre el uso de un meridiano universal comenzaron en 1884, cuando los protocolos de la conferencia internacional del meridiano, celebrada en octubre del mismo año en Washington para la adopción del meridiano de Greenwich fueron remitidos por la delegación chilena en la conferencia al Ministerio de Instrucción Pública (UNIVERSIDAD DE CHILE, 1884, tomo 65, sección 1, p. 424-470). Las resoluciones de dicho congreso son transcritas y traducidas el año siguiente (UNIVERSIDAD DE CHILE, 1885, tomo 68, sección 1, p. 41-42).
}

(c) Urbana: Rev. Eletrônica Cent. Interdiscip. Estud. Cid. Campinas, SP V.10, n.1 [18] 
noche el cielo y de día... la ciudad. Entre las imágenes que produce esta expedición encontramos una vista panorámica de Santiago, elaborada a partir de bocetos realizados con cámara (probablemente una cámara lúcida) por el artista estadounidense Edmond Reuel Smith (figura 13).

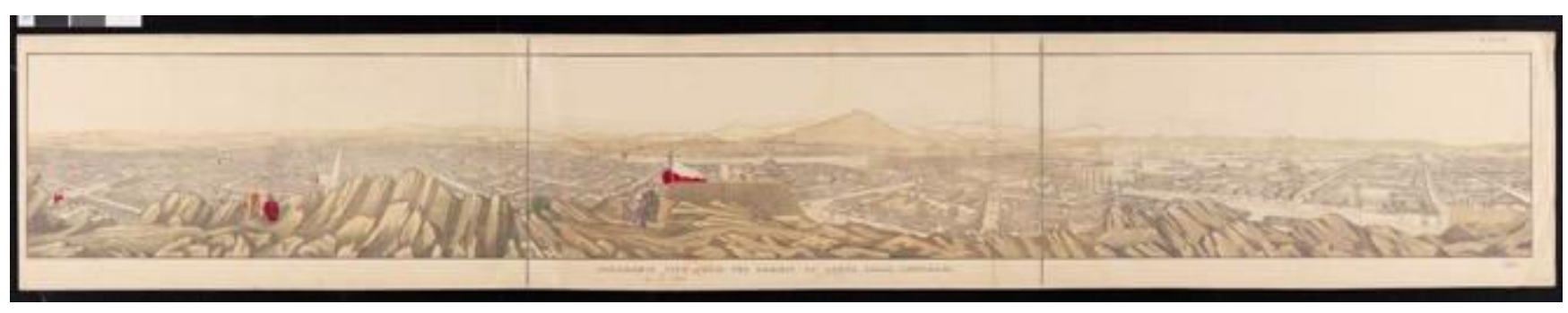

Fig. 13 - Edmond Reuel Smith (dibujante). Panoramic view from the summit of Santa Lucía (Santiago), 1855, grabado por T. Sinclairs lithographers, Philadelphia. Biblioteca Nacional de Francia, París. Fuente:

http://www.archivovisual.cl/panoramic-view-from-the-summit-of-santa-lucia-santiago, consultado el 19 abril 2017.

Existen al menos otras tres representaciones de tipo panorámico anteriores y posteriores que confirman al cerro como punto de vista privilegiado para observar la ciudad: la impresa en varias láminas a partir de dibujos acuarelados del marino inglés William Waldergrave de 1823 (figura 14), el grabado realizado a partir de dibujos de T. R. Harvey en 1850 (figura 15) y la lámina de Pierre Dejean publicada en 1867 (figura 16). 

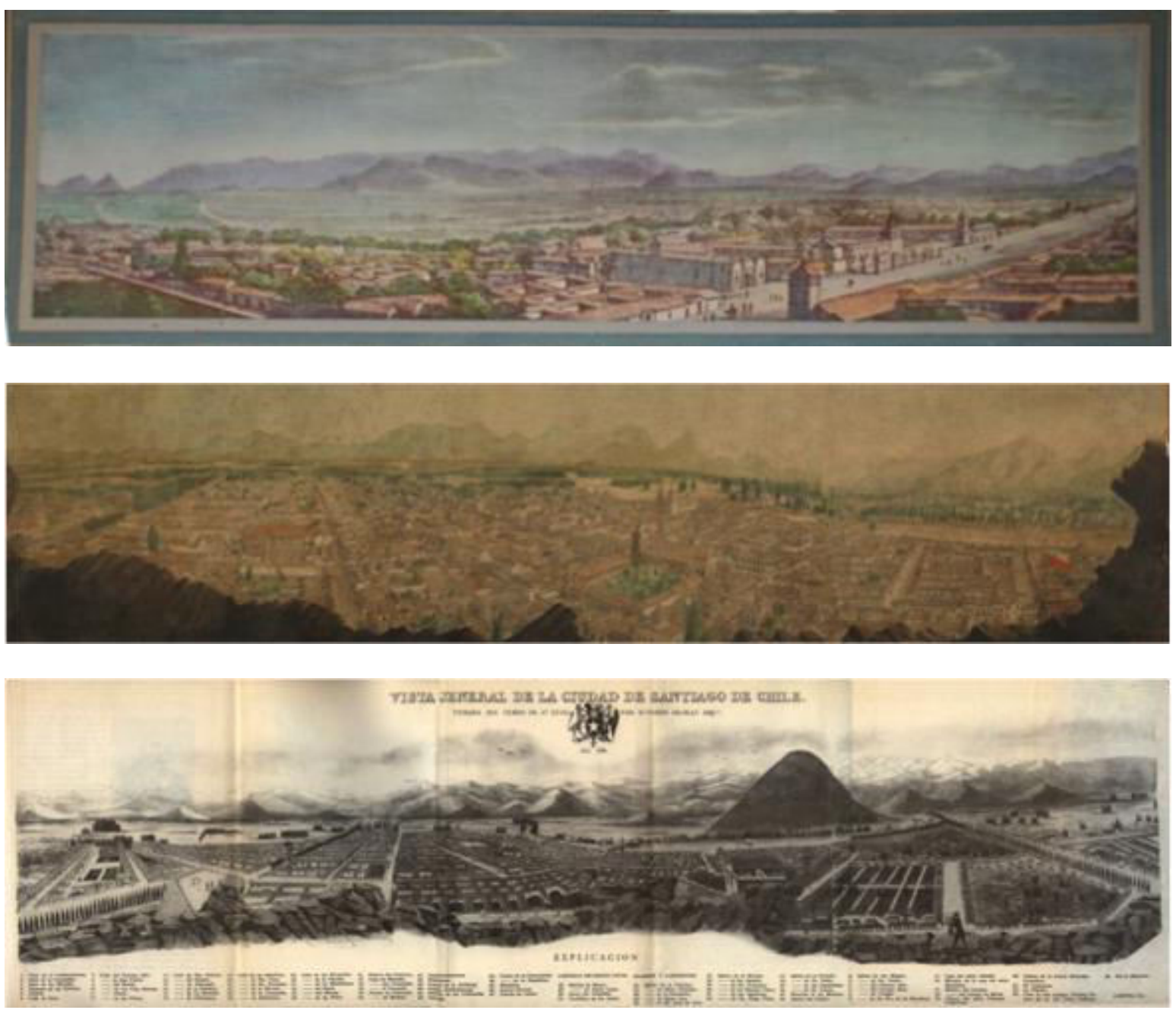

Fig. 14 - William Waldegrave (dibujante), Vistas panorámicas de Santiago, la capital de Chile, 1823, Litografía de Agostino Aglio. Museo Histórico Nacional, Santiago.

Fig. 15 - T. R. Harvey, Santiago, vista desde el Santa Lucía, c. 1850. Museo Histórico Nacional, Santiago.

Fig. 16 - Pedro Dejean, Vista jeneral de la ciudad de Santiago de Chile, tomada del cerro Santa Lucía por don Pedro Dejean Arquitecto, 1867. Archivo desconocido.

Estas cuatro imágenes panorámicas subrayan la meridionalidad del cerro, dando cuenta del emplazamiento de la ciudad en el valle del Río Mapocho. Todas incluyen al fondo el perfil de montaña, elemento visual característico de composiciones horizontales realizadas desde puntos de vista únicos (elevados o distantes, terrestres o marítimos), que contribuyen a generar el efecto de continuidad en la representación. ${ }^{7} \mathrm{Si}$ bien en ellas se evidencia -figurativa y textualmente- un

7 Los perfiles de montaña se hicieron tan habituales (como parte de una imagen o como una imagen autónoma) que son ya consideradas un género dentro de la paisajística del XIX. Un ejemplo emblemático es el Esbozo de las principales alturas de los dos continentes, dibujo que Goethe dedica a Humboldt hacia 1807

(c) Urbana: Rev. Eletrônica Cent. Interdiscip. Estud. Cid. Campinas, SP v.10, n.1 [18] p.232-249 jan./mai. 2018 
intento de vista general o total, la que más se aproxima al dispositivo panorámico de Barker es la compuesta a partir de los esbozos de Smith, que combina la precisión del detalle con la visión en $360^{\circ}$. Construida a partir de múltiples líneas de perspectiva trazadas a partir de un punto de vista cuya altura es equivalente a la de los ojos (que en este caso, se potencian con aparatos ópticos) la imagen es, por supuesto, un documento de cómo lucía la ciudad a mediados del siglo XIX. Pero es igualmente documento de una práctica del dibujo como modo de conocimiento y de la confluencia de los campos de las artes y de las ciencias en la cultura visual. La persistencia de la representación panorámica de Santiago desde el cerro Santa Lucía da cuentas, además, del gusto que los espectadores (habitantes y viajeros) experimentan por este tipo de imágenes, cada vez más disponibles gracias a las posibilidades de su reproducción técnica en grabado. Similar a la fotografía de Manoury ya comentada, las cuatro imágenes dejan dentro del marco de representación fragmentos del cerro, su superficie rocosa que retrata los famosos basaltos columnares, comentados por cada viajero naturalista que ponía los pies en la ciudad y aún visibles hoy. Más allá de la particular verosimilitud, precisión, orientación, técnica y estilo, circulación entre otros aspectos que podrían analizarse en relación a cada una de estas imágenes, nos interesa señalar el gesto que comparten: convertir al cerro en una suerte de prótesis ocular desde la cual se extiende -y se confirma- el poder de la mirada.

Es probable que uno de los motivos de suceso de las vistas panorámicas en este periodo sea el hecho de que se trata de imágenes que ubican a su espectador en el mismo punto desde el cual esta fue construida, es decir, al centro de la misma, provocando un efecto de identificación y un traspaso de la experiencia de observar un lugar en directo. Esto se explicita aún más en obras únicas de artistas viajeros como el conocido artista bávaro Johan Moritz Rugendas (figura 17) y el menos conocido pintor italiano Giovatto Mollinelli (figura 18). Son piezas que describen la vista desde el cerro por medio de técnicas propias del trabajo al aire libre, como el croquis, la acuarela y óleos de pequeño formato, expresivas de la experiencia subjetiva de paisaje. El panorama de Rugendas (cuyo título puede haber sido atribuido a posteriori) fue probablemente realizado también con cámara lúcida y, muy probablemente, sirvió al artista como base para las numerosas pinturas y dibujos que realizó de la ciudad a partir del cerro, agregando y restando personajes. La vista de Mollinelli, por su parte, registra la vista del sector oriente de la ciudad, enmarcado por las altas cimas andinas y las tierras altas del Mapocho que por entonces eran aún terrenos agrícolas. La pintura registra además una emoción, o por lo menos, convoca la sensación de ensimismamiento que debe haber embargado esa mañana al pintor genovés ante el paisaje santiaguino.

luego de leer su Ensayo sobre la geografía de las plantas... (DIENER 2015). El historiador suizo François Walter (WALTER 2004) ha estudiado estos perfiles de montaña como un tipo de imagen que rebalsó la cartografía especializada y se convirtió en un artefacto de la cultura de imprenta de la segunda mitad del XIX. En afiches, láminas y postales, cumplía a la vez un fin divulgatorio y didáctico para la historia natural, un fin artístico vinculado al gusto por los viajes y propagandístico de las nuevas imágenes-país que se gestaron con gran éxito en Europa valiéndose fundamentalmente de recursos paisajísticos. Estas vistas panorámicas se inscriben con toda pertinencia dentro de esta categoría.

(c) Urbana: Rev. Eletrônica Cent. Interdiscip. Estud. Cid. Campinas, SP $\quad$ v.10, n.1 [18] p.232-249 jan./mai. 2018 


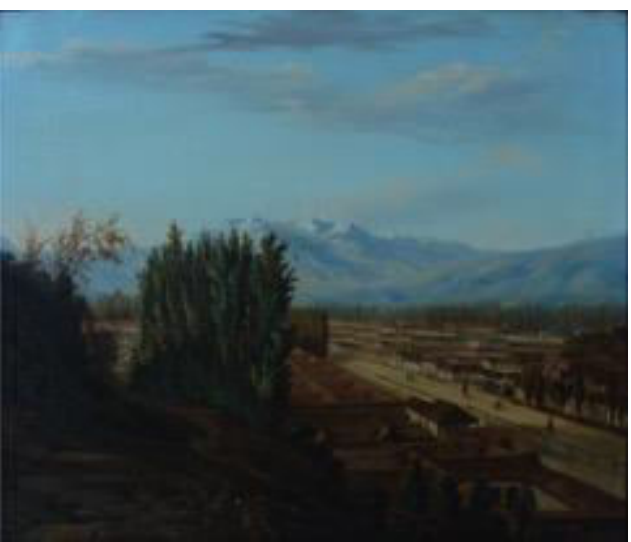

Fig. 17 - Johann Moritz Rugendas, Panorama de Santiago, c. 1835. Staatliche Graphische Sammlung, Munich.

Fig. 18 - Giovatto Molinelli, Antigua Cañada de Santiago, 1861. Museo Nacional de Bellas Artes, Santiago.

\section{El cerro como mirador}

Agente fundamental de la modernización de Santiago, el intendente Benjamín Vicuña Mackenna emprendió, entre 1872 y 1875 , intensos trabajos en el cerro para convertirlo en paseo público. Esta obra, una de las más emblemáticas del conjunto de intervenciones urbanas promovidas por el activo político e intelectual, estaba dirigida a formar un nuevo tipo de ciudadanía, fundada en los principios positivistas de la higiene social y en el urbanismo moderno de tradición estadounidense y francesa (WEHNER, 2000). Para Vicuña Mackenna, la antropización de espacios naturales, que implicaba ahora la inclusión de obras de arte y la delimitación de sitios de contemplación, constituía una manera de sanear la ciudad, desagraviar la fuerza invasiva, rústica y bárbara de las chimbas ${ }^{8}$, alejar las huellas coloniales que aún la marcaban e imponer ideales de progreso provenientes de las principales urbes mundiales. En propias palabras de Vicuña Mackenna, el cerro debía ser apreciado como "un verdadero paseo, en el sentido moderno de la palabra, que significa recreo i arte, salud e hijiene" (VICUÑA MACKENNA, 1874, p. 6).

Al momento de su inauguración, el parque mirador del cerro Santa Lucía fue presentado al público por medio de un álbum fotográfico, otra muestra más del impulso de modernidad que animaba a este proyecto. El autor de la mayor parte de las fotografías fue el francés avecindado en Chile Pedro Emilio Garreaud. Este álbum, que retrata los distintos parajes y objetos decorativos que adornaban el recorrido, se reproduce el efecto del paseante al incluir una serie de vistas de Santiago apreciables desde el cerro. Entre las 48 fotografías del álbum, una docena de imágenes reconstruye la visión de la ciudad a la manera circular, con tomas hechas contorneando el monte (figuras 19-24, que corresponde a una selección de vistas incluidas en el Álbum).

\footnotetext{
${ }^{8}$ La Chimba ("de la otra orilla", en idioma quechua) era el nombre con el que se designaba el sector de la ribera norte del Río Mapocho durante la colonia y el siglo XIX, donde se congregaban asentamientos indígenas y de mestizos mayoritariamente dedicados a la servidumbre, además de artesanos.
}

(c) Urbana: Rev. Eletrônica Cent. Interdiscip. Estud. Cid. Campinas, SP v.10, n.1 [18] p.232-249 jan./mai. 2018 

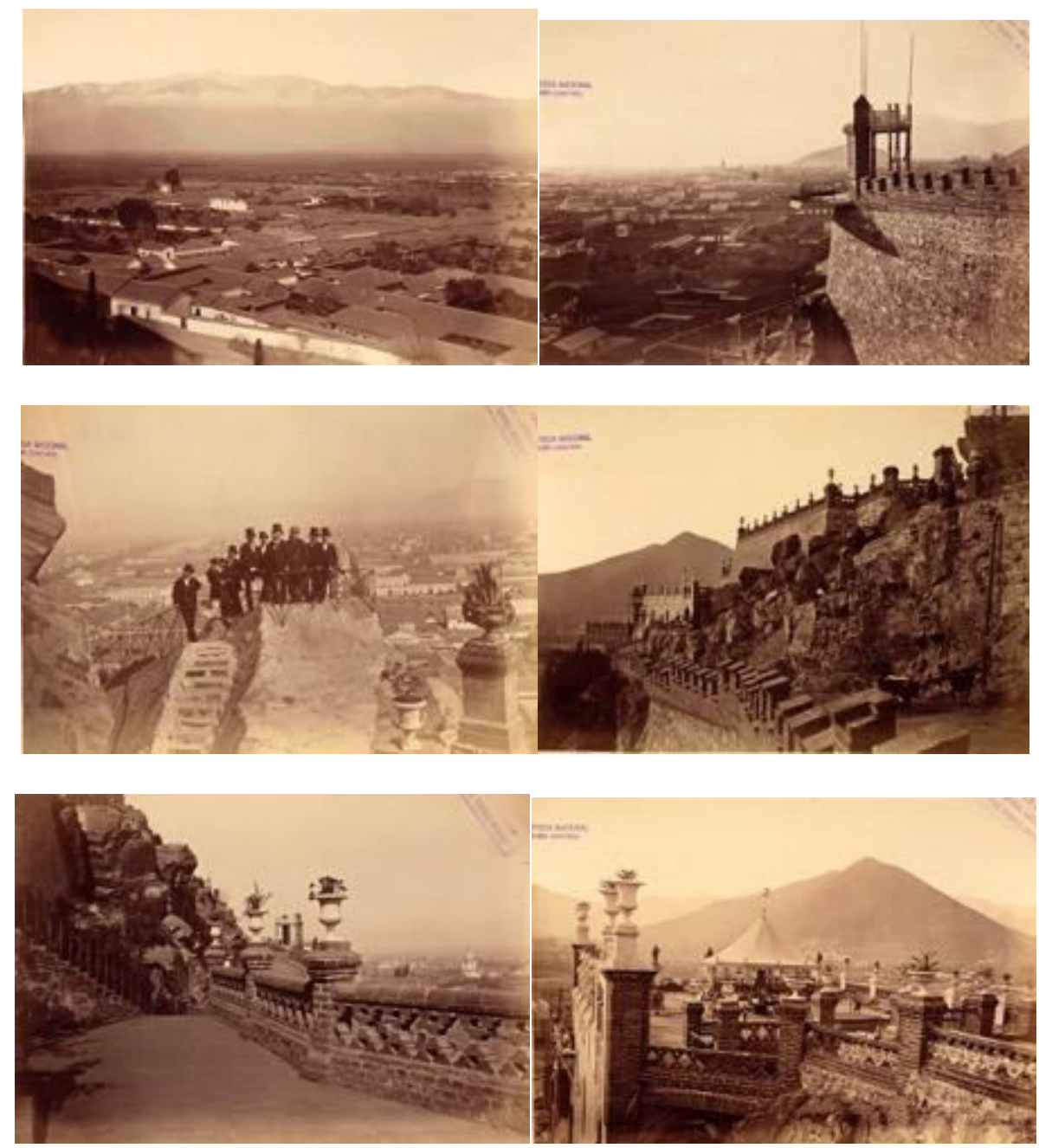

Figs. 19-24 - Pedro Emilio Garreaud, Divisadero del Santa Lucía; El balcón volado; La roca Tarpeya; El camino del poniente; La meseta del estanque; Terraza de Hidalgo; en Álbum del Santa Lucía, lo que es i lo que debería ser: segunda memoria de los trabajos ejecutados desde el 10 de septiembre de 1872 al 15 de marzo del presente año, Santiago: Imprenta de la librería del Mercurio, 1874. Biblioteca Nacional de Chile, Santiago. Fuente: http://www.memoriachilena.cl/archivos2/pdfs/MC0006534.pdf, consultado el 19 abril 2017.
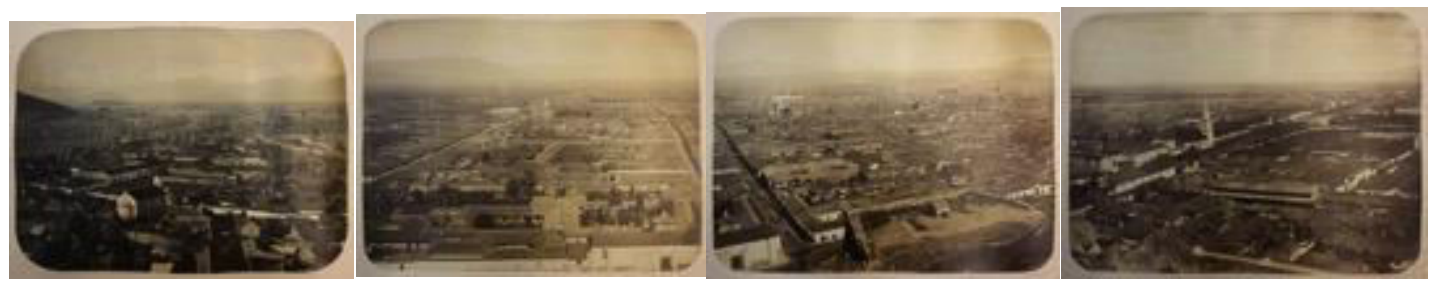

Figs. 25-28. Eugène Maunoury, Vue générale; Rues du Lira et du Carmen; Rue Sainte Rose et fort Sainte Lucie; Église de San Francisco et la Promenade; en Andenken an Chile, c. 1865. Bibliothèque Nationale de France. Fuente: http://gallica.bnf.fr/ark:/12148/btv1b8443045p, consultado el 19 abril 2017. 
El álbum no incluyó un panorama completo que fuera tomado, por ejemplo, desde alguno de los miradores más altos del paseo y produjera una fotografía compuesta -siguiendo el ejemplo de las fotografías secuenciales que Eugène Maunoury tomó en la década anterior (figuras 25-28)o realizada con cámaras ad hoc disponibles ya para la época. Pero es en la propia experiencia panorámica, en el paseo mismo, que se logra esta vista, posibilitada por terrazas, miradores e incluso muros almenados que restituyen, varias décadas después de la construcción de las primeras baterías militares, la condición de mirilla del cerro. En palabras del intendente: "Esta sesta perspectiva [se refiere a una de las fotografías de Garreaud] completa la precedente i sirve para desarrollar la admirable formación circular del Santa Lucía en toda su accidentada circunferencia [...] Por esto el artista ha procedido acertadamente al circumbalar el cerro con el foco de su máquina, a fin de exhibirlo en este Álbum como un verdadero diorama en una tela sin fin" (VICUÑA MACKENNA, 1874: plancha VI). A todas luces, el intendente confunde los dispositivos visuales panorama y diorama, dando señas de la novedad del término y de su polisemía. Al usar este término, el intendente da cuenta también de una economía léxica que sintetiza las sucesivas funciones del cerro que hasta aquí hemos venido constatando; una sola palabra sirve para resumir lo que cien años antes el historiador Vicente de Carvallo y Goyeneche había tenido que describir usando una larga oración: "I como [el cerro Santa Lucía] está en el estremo oriental de la población, sirve de vistoso paseo, porque dominándola rejistra el valle por todos cuatro vientos sin que pueda ocultarse a la vista la más distante hondada" (CARVALLO y GOYENECHE, 1875-76, tomo X: 30, subrayado en la fuente). El parque-mirador, como una segunda naturaleza y simulacro paisajístico se emplaza sobre el peñón

El término diorama, tal como es usado por Vicuña Mackenna, no describe solamente la vista en $360^{\circ}$ desde un punto de vista fijo, sino que se refiere un modo de habitar el cerro. Tanto el diseño de las terrazas del paseo como las fotografías del álbum responden así a la estrategia del panorama, asegurando la cobertura de la visión en torno a todo el diámetro del monte y la vista circular de Santiago (HIDALGO, 2009). Con la inauguración del paseo público y establecida ya la antropización del cerro -habitada no sólo por el cantero, el cartógrafo, el científico y el artista, sino también por todo aquel que accede a convertirse en paseante y turista-, la mirada panorámica se fija como una mirada urbana y moderna, expresada a través de la arquitectura instalada en el cerro y de las representaciones que desde allí se hicieron de la ciudad. El espacio que en distintos momentos y sentidos ha servido para dominar la ciudad, se redefine una vez más para cumplir ahora el dominio de clase que, al mismo tiempo de imponer un sistema social, impone un gusto, hábitos y un orden a la ciudad y a sus habitantes (VICUÑA, 1996).

La mirada panorámica que se configura desde el cerro es, como hemos visto, el resultado de prácticas de ocupación y visiones del territorio propios a diferentes momentos y actores sociales. La secuencia de imágenes que hemos analizado en estas páginas constituye una suerte de biografía visual del Santa Lucía, fragmentaria, parcial, pero suficientemente elocuente como para evidenciar que el cerro fue cambiando tanto como la cuidad, desprendiéndose de su condición natural para activarse como una potencial arma de guerra, un implemento científico, un utensilio artístico, una infraestructura de ordenamiento social, una prolongación al fin de la acción humana. Cada una de ellas funciona como documento no solo de lo que se ve sino también de cómo se ve desde la cima de un cerro. En este caso, una ciudad en plena transformación y un modo de ver que se entiende como experiencia, conocimiento y apropiación por medio de su autorepresentación.

(c) Urbana: Rev. Eletrônica Cent. Interdiscip. Estud. Cid. Campinas, SP v.10, n.1 [18] p.232-249 jan./mai. 2018 
DOI: $10.20396 /$ urbana.v10i1.8648813

\section{Bibliografía}

AMUNÁTEGUI, Miguel Luis i Gregorio Víctor. La reconquista española: apuntes para la historia de Chile: 1814-1817. Santiago: Imprenta Chilena, 1851.

BARROS ARANA, Diego. Historia general de Chile, tomo X. Santiago: Editorial Universitaria, 18811902.

BENJAMIN, Walter. El libro de los pasajes. Madrid: Akal, 2011 [1935].

BENJAMIN, Walter. La obra de arte en la época de su reproductibilidad técnica. Buenos Aires: Amorrortu, 2013 [1936].

BRAVO LIRA, Bernardino. El absolutismo ilustrado en Hispanoamérica, Chile (1760-1860): de Carlos III a Portales y Montt. Santiago: Universitaria, 1994.

BUENO SIQUEIRA, Beatriz Desenho e Desígnio. O Brasil dos engenheiros militares (1500-1822). São Paulo: FAPESP - EDUSP, 2011.

CARVALLO Y GOYENECHE, Vicente de. Descripción histórico-jeográfica del reino de Chile. Santiago: Imprenta del Mercurio, 1875-76 [1796], tomo X.

DEBORD, Guy. La sociedad del espectáculo. Valencia: Pre-textos, 2002 [1967].

DIENER, Pablo. "Dibujo del natural y paisaje". Memorias del Primer Coloquio de Investigaciones en Historia del Arte, Línea y lugar. Invitación a pensar el dibujo. Santiago: UAH y MNBA, 2015.

GUERRERO L., Cristián. La contrarrevolución de la Independencia de Chile. Santiago: Editorial Universitaria, 2002.

HIDALGO, Germán. «Panoramic view and national identity. Two of Santiago de Chile's public spaces in the second half of the nineteenth century ». En Planning perspectives, Vol. 24, n. 3, Julio 2009, p. 319-347.

HUFFMAN, Wendell W. "The United States Naval Astronominal Expedition (1849-52) for the Solar Parallax". Journal for the History of Astronomy, Vol.22, NO.69/3/AUG, P.208, 1991, p. 208-220.

FELIÚ CRUZ, Guillermo. Vida de don Manuel Antonio Talavera: primer cronista de la Revolución de la Independencia de Chile. Santiago: Imprenta del Cóndor, 1937.

GONZÁLEZ LEIVA, José Ignacio. "Primeros levantamientos cartográficos generales de Chile con base científica: los mapas de Claudio Gay y Amado Pissis". En: Revista de Geografía del Norte Grande, n. 38, 2007, p. 21-44.

GREVE, Ernesto. Historia de la ingeniería en Chile. Santiago: Imprenta Universitaria, 1938.

GUARDA, Gabriel. Flandes Indianos: las fortificaciones del reino de Chile, 1541-1826. Santiago: Universidad Católica de Chile, 1990.

(c) Urbana: Rev. Eletrônica Cent. Interdiscip. Estud. Cid. Campinas, SP v.10, n.1 [18] p.232-249 jan./mai. 2018 
GUARDA, Gabriel. "El Mariscal de Campo don Manuel Olaguer Feliú, Director del Real Cuerpo de Ingenieros". En: Homenaje a Guillermo Feliú Cruz. Editorial Andrés Bello. Santiago de Chile, 1973.

OLEKSIJCZUK, Denise Blake. The first Panoramas. Visions of British Imperialism. Minnesota Press, 2000.

PELIOWSKI, Amarí. Traces de modernité: pratiques et fonctions du dessin d'architecture aux Lumières au Chili, 1762-1797. Tesis doctoral, École des Hautes Études en Sciences Sociales (EHESS), París, 2015 (inédita).

PÉREZ DE ARCE, Rodrigo Pérez de Arce; ASTABURUAGA, Ricardo; RODRÍGUEZ, Hernán. La montaña mágica: el cerro Santa Lucía y la ciudad de Santiago. Santiago: Ediciones ARQ, 1993.

PÉREZ DE ARCE, Rodrigo "Cruzando el vacío del Llano del Maipo", en Archivo Visual de Santiago, http://www.archivovisual.cl/cruzando-el-vacio-del-Ilano-del-maipo, consultado el 19 abril 2017.

PICON, Antoine. Architectes et ingénieurs au Siècle des Lumières. Marseille : Éditions Parenthèses, 1988.

PICON, Antoine. L'invention de l'ingénieur moderne. L'école des Ponts et Chaussées, 1747-1851. Paris : Presses de l'École Nationale des Ponts et Chaussées, 1992.

PISSIS, José Pedro Amado. Geografía física de la República de Chile. París: Instituto Geográfico de París, Ch. Delagrave, editor de la Sociedad Geográfica, 1875.

SAGREDO, Rafael; González Leiva, José Ignacio. La expedición Malaspina en la frontera austral del imperio español. Santiago: Editorial Universitaria, 2004.

SALAZAR, Criss. "El Huelén negro: primera etapa de la historia del cerro Santa Lucía (15401852), en Urbatorium, http://urbatorium.blogspot.com.es/2009/07/el-huelen-negro-primeraetapa-de-la.html, consultado el 19 abril 2017.

UNIVERSIDAD DE CHILE. "Meridiano común: protocolos de la conferencia internacional celebrada en Washington para la adopción de un meridiano único, remitidos por la delegación chilena al Ministerio de Instrucción Pública i aquí traducidos", Anales de la Universidad de Chile. Santiago: 1884

UNIVERSIDAD DE CHILE. "Comunicaciones del delegado de Chile ante el Congreso astronómico de Washington", Anales de la Universidad de Chile. Santiago: 1885.

VICUÑA, Manuel. El París Americano. La oligarquía chilena como actor urbano en el siglo XIX. Santiago: Universidad Finis Terrae y Museo Histórico Nacional, 1996.

VICUÑA MACKENNA, Benjamín. Historia crítica y social de la ciudad de Santiago: desde su fundación hasta nuestros días (1541-1868). Valparaíso: Imprenta de El Mercurio, 1869.

VICUÑA MACKENNA, Benjamín. Álbum del Santa Lucía. Colección de las principales vistas, monumentos, jardines, estatuas i obras de este paseo, dedicado a la Municipalidad de Santiago

(c) Urbana: Rev. Eletrônica Cent. Interdiscip. Estud. Cid. Campinas, SP v.10, n.1 [18] p.232-249 jan./mai. 2018 
DOI: $10.20396 /$ urbana.v10i1.8648813

por su actual presidente, B. Vicuña Mackenna. Santiago de Chile: Imprenta de la Librería del Mercurio, 1874.

WALTER, François. Les figures paysagères de la nation. Territoire et paysage en Europe (16e-20e siècle). París: EHESS, 2004.

WEHNER, Leslie. Benjamín Vicuña Mackenna: génesis de la transformación de Santiago. Tesis de licenciatura. Santiago: Universidad Católica de Chile, 2000. 